This item was submitted to Loughborough's Institutional Repository by the author and is made available under the following Creative Commons Licence conditions.

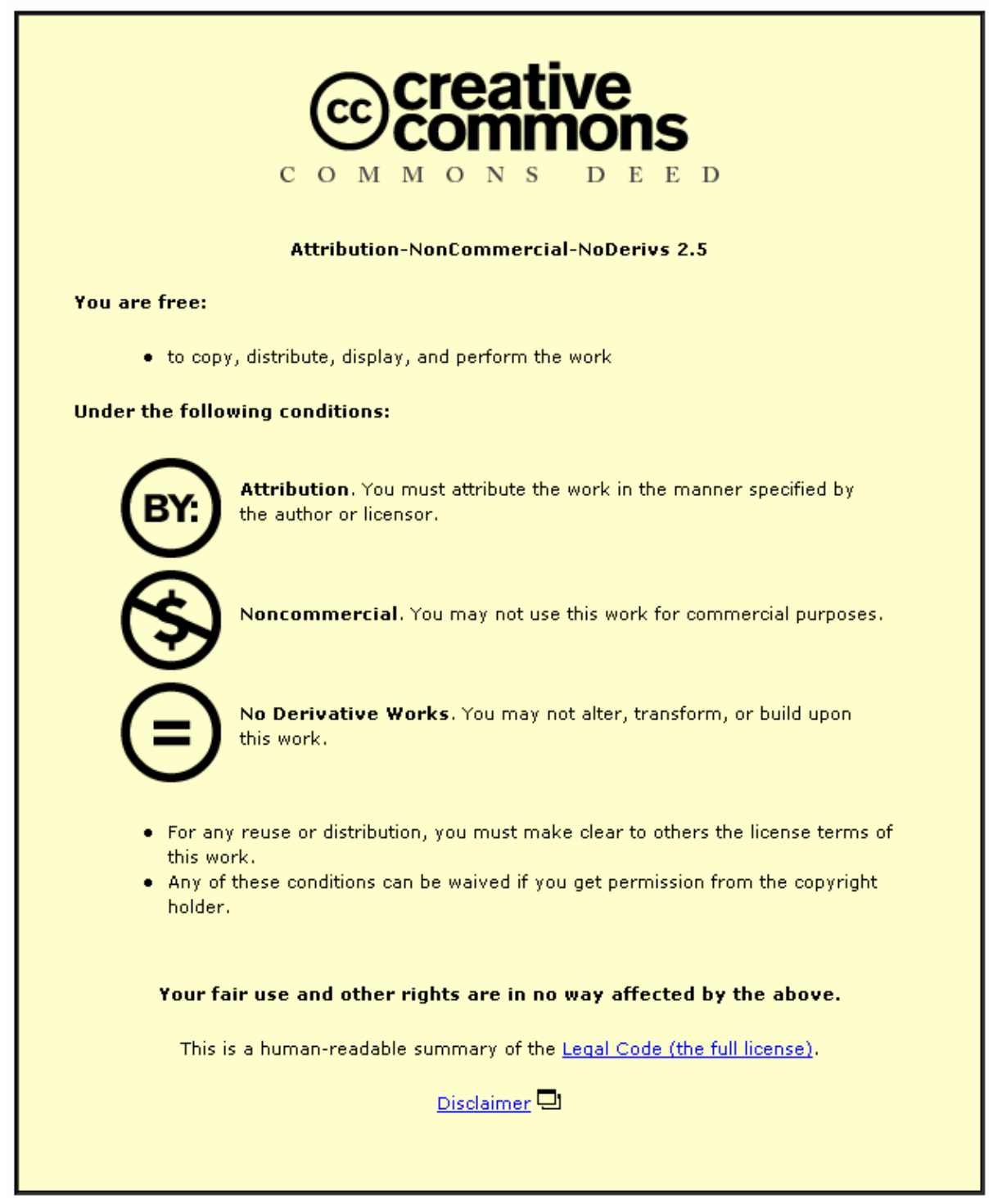

For the full text of this licence, please go to: http://creativecommons.org/licenses/by-nc-nd/2.5/ 
(C)2008, American Society of Heating, Refrigerating and Air-Conditioning Engineers, Inc. (www.ashrae.org). Published in HVAC\&R Research, Vol. 14, No. 1, January 2008. For personal use only. Additional reproduction, distribution, or transmission in either print or digital form is not permitted without ASHRAE's prior written permission.

\section{Evolutionary Synthesis of HVAC System Configurations: Experimental Results}

\author{
Jonathan Wright, PhD, CEng \\ Member ASHRAE
}

\author{
Yi Zhang, PhD \\ Member ASHRAE
}

Received October 3, 2006; accepted October 5, 2007

The aim of this research was to investigate the synthesis of novel heating, ventilating, and air conditioning (HVAC) system configurations using model-based optimization methods (Wright et al. 2008). This paper describes the experimental results for the optimization of a two-zone HVAC system of a building located in a continental climate. The goal of the optimization was to find a feasible system design that operated with the minimum system capacity at each load condition.

The optimization method used in this research is based on a Genetic Algorithm search method. The robustness of the optimization was examined through the consistency of the design solutions found from multiple runs of the algorithm (each run being subject to different initial conditions). The results indicate that given two runs of the algorithm, there was a high probability of finding a system design that has a performance comparable to existing system configurations. Given eight runs of the algorithm, it is probable that the best system found would have a performance that exceeded that of existing system configurations. However, approximately one third of all optimization runs would converge onto an infeasible system configuration, the elimination of this characteristic being the subject of future research.

The optimality of the synthesized systems was judged in comparison to the performance of three benchmark systems and by comparing the system capacity to the minimum possible at a given load condition. The best of the synthesized systems had a performance that exceeded that of the conventional benchmark systems and that was comparable to that of a conceptually optimum system configuration. The system capacity was also close to the minimum possible capacity and as such was judged to be a near-optimum system configuration for the example building.

It can be concluded that the optimization approach is able to synthesize near-optimum system configurations that have a performance equal to or better than existing system configurations. The algorithm, however, requires multiple runs in order to find reliable solutions, a fact that should be addressed in future research. The current algorithm, however, represents a significant step toward the design of software systems that are able to synthesize new and optimum HVAC system configurations.

\section{INTRODUCTION}

Previous research has demonstrated that the capital, operating, or life-cycle cost of a building can be reduced through the use of model-based numerical optimization methods. To date, such research has been concerned with the optimization of building construction (Caldas and Norford 2002; Wang et al. 2005), HVAC system size (Wright 1996), HVAC system supervisory control (Nassif et al. 2005), and the simultaneous optimization of building construction, HVAC system

Jonathan Wright is a professor of building optimization in the Department of Civil and Building Engineering, Loughborough University, Loughborough, United Kingdom. Yi Zhang is a senior research fellow for the Institute of Energy and Sustainable Development, De Montfort University, Leicester, United Kingdom. 
size, and system supervisory control (Wright et al. 2002). However, there is no previous research into the optimization of HVAC system configurations.

This paper presents the results of a study into the model-based optimization of HVAC system configurations (the optimization procedure described by Wright et al. [2008]). The aim of the optimization is to simultaneously find a system topology and operating strategy that minimizes the system energy use. Two groups of problem variables are optimized; the first group describes the connection between a fixed set of components (the system topology), and the second group describes the system operation at a number of load conditions. For each load condition, the system operation is specified by the capacity of the components and the airflow rates throughout the system. The system's energy use is defined to be a weighted sum of the total system capacity at each load condition. ${ }^{1}$ The optimization problem is also subject to a number of constraints that ensure the feasibility of the topology and system operation (Wright et al. 2008).

The optimization problem has been solved using a Genetic Algorithm (GA) search method (Wright et al. 2008). Since GAs use probabilistic search operators and in general do not test for formal convergence of the search, there can be a degree of uncertainty associated with the optimality of the solutions. In this respect, the experiments described herein have been designed to evaluate both the repeatability of the optimization as well as the potential of the approach to synthesize near-optimum HVAC system configurations.

\section{EXPERIMENTAL APPROACH}

There are three factors considered in judging the performance of the optimization algorithm:

- The procedure for judging the robustness of the optimization algorithm, robustness being defined in terms of the consistency of the solutions obtained from a number of different optimization runs.

- The method by which the optimality of the solutions can be evaluated.

- The design of a representative optimization problem.

\section{Examination of Algorithm Robustness}

The GA used to solve this optimization problem uses a pseudo-random number sequence as part of its probabilistic search operators and to initialize the search with the first set of trail solutions (Wright et al. 2008). A change to the pseudo-random number sequence is therefore likely to result in a change in the behavior of the search and possibly the "optimum" solution found by the search. The robustness of the algorithm has therefore been examined by comparing the solutions from a number of optimization runs for the same problem, with each run using a different pseudo-random number sequence. In this study, solutions from over 40 different trial optimizations have been compared, the pseudo-random number sequence used in each trial having been initialized with separate time-dependent seeds.

\section{Evaluation of System Optimality}

The performance of the synthesized systems has been compared to three benchmark systems, two of these based on conventional system configurations. The third is a conceptually optimum system configuration derived from an analysis of HVAC system performance (Wright et al. 2004; Zhang et al. 2006). The operation of the benchmark systems has been optimized in the same manner as for the synthesized systems, ${ }^{2}$ which ensures that a difference in performance

1. Note that the term capacity is used here to denote the instantaneous rate of energy flow at a given operating point; the term capacity is therefore not restricted to the "peak" duty of the system but applies equally to all load conditions.

2. This was done by optimizing the airflow rates and component capacities at each load condition. 
between systems is a function of the system configurations rather than the manner in which the systems are controlled.

The optimality of the synthesized systems has also been evaluated by comparing the systems' capacities to the minimum possible capacity at each load condition.

Minimum System Capacity and System Effectiveness. The minimum capacity of a system can be considered in two parts; first, the fan capacity required to move the air through the system, and second, the sensible and latent capacities associated with the heating, cooling, humidification, and dehumidification processes (the air-conditioning processes). Conceptually, it has been argued that the minimum possible fan capacity should be taken as zero (Wright and Zhang n.d.). However, for a multizone system, the minimum capacity associated with the air-conditioning processes is a function of the extent to which the zone loads may be offset by the transfer of energy between zones (Wright and Zhang n.d.). The mechanism for energy transfer between zones considered here is interzonal airflow and, therefore, the minimum system air-conditioning capacity at a given load condition is equivalent to the sum of the zone and outdoor air loads on each zone after the zone loads have been minimized through the use of interzonal airflow. For systems conditioning a small number of zones, the minimum system capacity can be calculated using a logic-based approach (Wright et al. 2004), although for systems serving more than two zones the calculation is likely to require the use of a model-based optimization method (Wright and Zhang n.d.).

The extent to which a system operates with the minimum capacity at a given load condition can be evaluated by a metric known as the system effectiveness, $\varepsilon_{i}$, this being given by

$$
\varepsilon_{i}=\left\{\begin{array}{c}
\frac{\dot{Q}_{i}^{\text {min }}}{\dot{Q}_{i}^{\text {system }}}, \dot{Q}_{i}^{\text {system }} \neq 0 \\
1.0, \dot{Q}_{i}^{\text {system }}=0
\end{array},\right.
$$

where

$\dot{Q}_{i}^{\text {min }}=$ minimum capacity at load condition $i$ and

$\dot{Q}_{i}^{\text {system }}=$ operating capacity of the system being evaluated (Wright and Zhang n.d.).

Equation 1 gives a number in the range 0.0 to 1.0 , a value of 1.0 indicating that the system operates with the minimum capacity (note, however, that due to the manner in which the minimum capacity has been calculated in this study, the system effectiveness can be greater than 1.0; see Appendix).

Equation 1 can also be extended to give the effectiveness of the system over a number of load conditions by:

$$
\varepsilon_{n}=\left\{\begin{array}{c}
\sum_{i=1}^{n} w_{i} \dot{Q}_{i}^{\text {min }} \\
\sum_{i=1}^{n} w_{i} \dot{Q}_{i}^{\text {system }} \\
\sum_{i=1}^{n} w_{i} \dot{Q}_{i}^{\text {system }} \neq 0 \\
1.0, \quad \sum_{i=1}^{n} w_{i} \dot{Q}_{i}^{\text {system }}=0
\end{array}\right.
$$


where

$w_{i}=$ weight applied to a given load condition

$n \quad=$ number of load conditions being considered

The weight $w_{i}$ represents (or is derived from) the time interval associated with the capacity at each load condition $i$.

Benchmark System Configurations. The benchmark system configurations, against which the performances of the synthesized (optimized) systems have been compared, are illustrated in Figures 1-3. Figures 1 and 2 illustrate "conventional" single-duct and dual-duct systems, the only unusual feature of these systems being the use of zone-based humidifiers (rather than a single centrally located humidifier). Figure 3 illustrates a conceptually optimum system configuration that resembles a fan-coil system with ductwork to allow the use of interzonal airflow. A detailed analysis of the performance characteristics of each of these systems is given by Wright et al. (2004) and Zhang et al. (2006). In brief, a system's energy use is a function of the extent to which it is able to operate with the minimum outdoor airflow rate, the need for simultaneous cooling and heating operation, and, finally, in the context of this research, the extent to which the system is able to minimize the zone loads by the use of interzonal airflow.

Both the single-duct and dual-duct systems use the central recirculation of the extract air from all zones. Where this is the case, the amount of outdoor air entering a particular zone is in proportion to the ratio of zone supply airflow rate to the total (mixed) airflow rate:

$$
\dot{m}_{i, z}^{\text {outdoor }}=\frac{\dot{m}_{i, z}^{\text {supply }}}{\dot{m}_{i}^{\text {total }}} \dot{m}_{i}^{\text {outdoor }, \text { total }}
$$

where

$$
\begin{array}{ll}
\dot{m}_{i}^{\text {total }} & =\text { mixed airflow rate in the main duct at load condition } i \\
\dot{m}_{i, z}^{\text {supply }} & =\text { corresponding supply airflow rate to zone } z \\
\dot{m}_{i}^{\text {outdoor }, \text { total }} & =\text { total outdoor airflow rate entering the system } \\
\dot{m}_{i, z}^{\text {outdoor }} & =\text { outdoor airflow rate entering zone } z
\end{array}
$$

Since for the system operation considered here the supply airflow rate to a particular zone, $\dot{m}_{i, z}^{\text {supply }}$, varies with the load conditions, it is likely that under some load conditions it will be necessary to increase the total outdoor airflow rate, $\dot{m}_{i}^{\text {outdoor, total }}$, above the ideal minimum so that the indoor air quality is maintained in all zones. This would result in some zones having a higher than desired outdoor airflow rate and increase the required system capacity above the minimum possible (Wright et al. 2004; Zhang et al. 2006). Although this applies to both the single-duct and dual-duct systems, it is not the case for the conceptually optimum system configuration (Figure 3) since there is no central recirculation of the extract air (in effect, each zone has an independent outdoor air supply).

Under some load conditions, the use of zone re-heaters also results in the single-duct system operating with the simultaneous cooling and heating of the supply air. However, for the two zone examples considered here, the mixing of air from the "hot" and "cold" ducts of the dual-duct system enables it to operate without the use of simultaneous cooling and heating and, therefore, with a lower system capacity than the single-duct system. This is also the case for the 


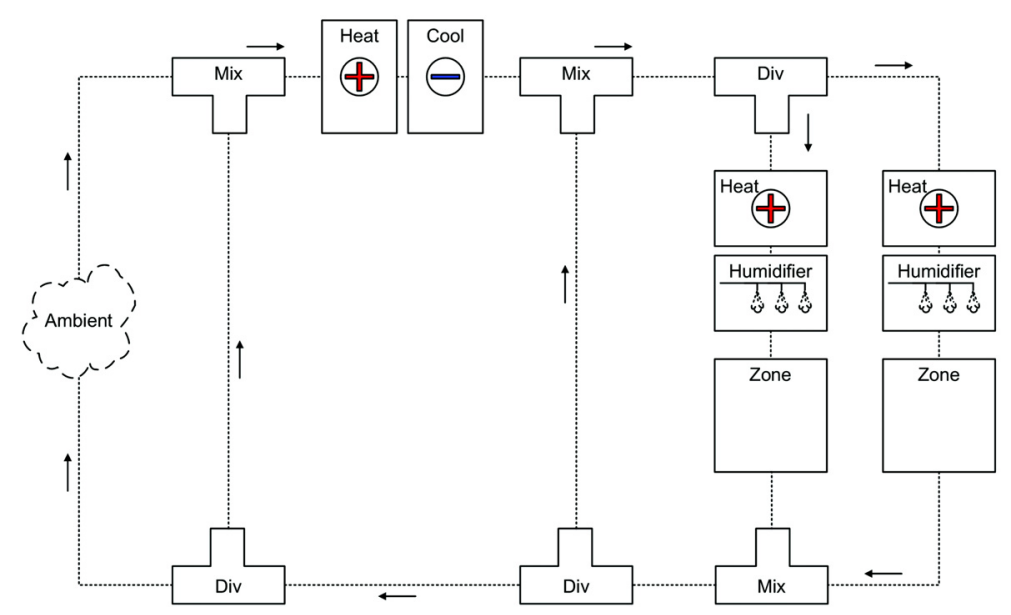

Figure 1. Single-duct system configuration.

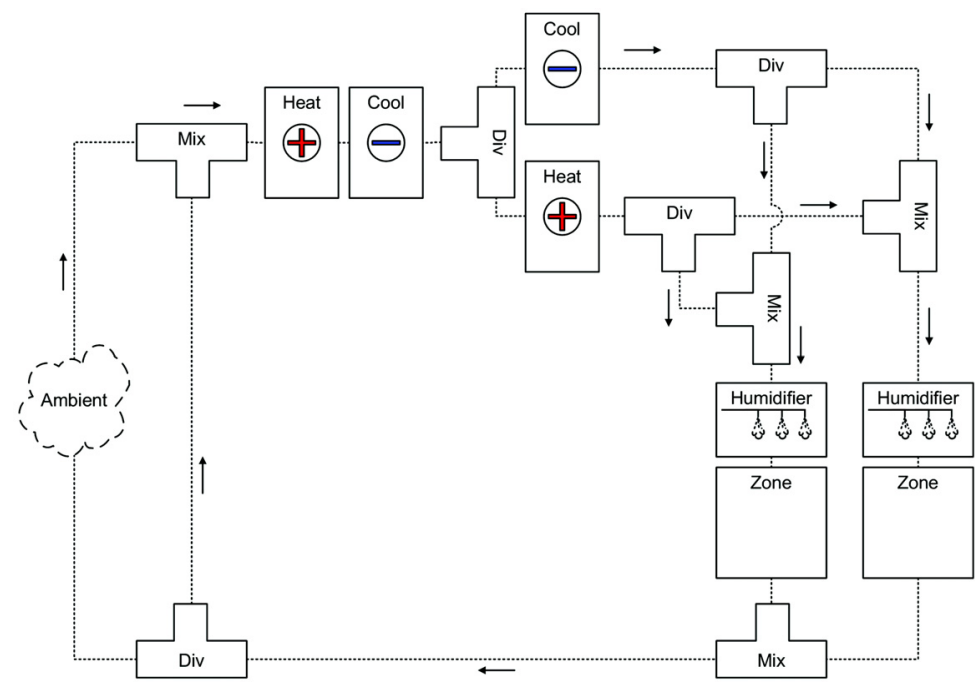

Figure 2. Dual-duct system configuration.

conceptually optimum system configuration, which uses distributed rather than centrally located air-conditioning components (the load in each zone being met by zone-specific air-conditioning components).

Finally, the only system that is effective in using interzonal airflow to offset the zone loads is the conceptually optimum system (Figure 3). Therefore, it can be concluded that the performance of the synthesized systems should be at least equal to that of the single-duct system (Figure 1) and preferably equal to that of the conceptually optimum system configuration (Figure 3).

\section{Example Optimization Problem}

The example optimization problem is for a system serving two mid-level zones of a multistory office building (Wright et al. 2004). Table 1 gives the set of components used in the example 


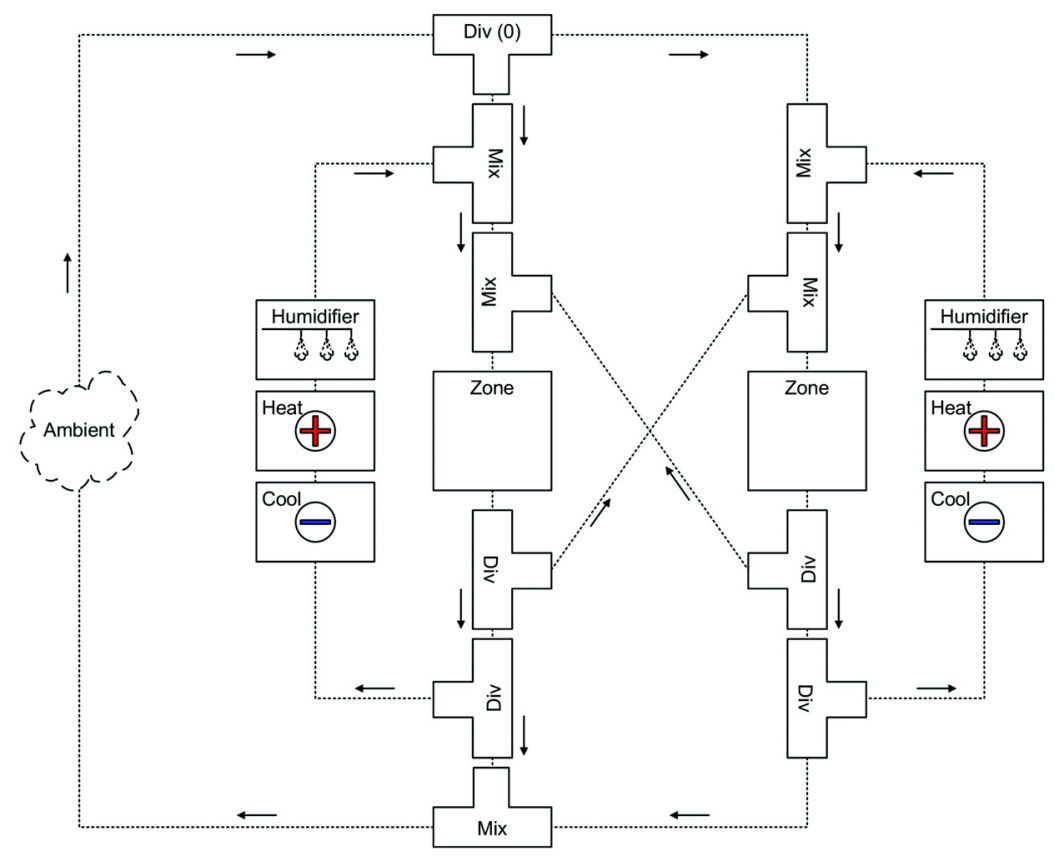

Figure 3. Conceptually optimum system configuration (fan-coil system with interzonal airflow).

Table 1. Optimization Problem Component Set

\begin{tabular}{cc}
\hline Component & Number \\
\hline \hline Airflow mixing "T" & 4 \\
Airflow diverting "T" & 4 \\
Heating coil & 2 \\
Cooling coil & 2 \\
Steam humidifier & 2 \\
\hline Zones & 2 \\
Ambient environment & 1 \\
\hline
\end{tabular}

optimization problem; note that strictly the zones and the ambient environment are part of the component set (Wright et al. 2008). The fans are excluded from the optimization since in the current optimization approach their location is considered to be a post-processing design exercise. The fan power is, however, calculated and included in the system capacity (Wright et al. 2008).

This component set would allow a system to be synthesized where each of the two zones was conditioned by a unique set of coils and humidifiers (as is the case for the conceptually optimum system configuration in Figure 3). Further, although the number of zones may be lower than served by many multizone systems, the component set results in a total of 120 optimization variables - 21 discrete variables for the system topology and 99 continuous variables for the system operation (Wright et al. 2008). The high number of optimization variables together with a topological search space in the order of $3.2 \times 10^{19}$ alternative topologies (Wright et al. 2008) indicates that this is a large-scale and challenging optimization problem. 
The optimization is also subject to a number of constraints formulated to ensure the feasibility of the system topology and system operation (Wright et al. 2008). The most difficult constraints to meet are concerned with ensuring that the system is able to offset the zone loads, this being defined in terms of the difference between the supply air conditions required to offset the zone loads and those resulting from the current system operation. This gives two equality constraints for each zone at each load condition, one constraint on the supply air temperature and a second on the supply air humidity ratio. Since equality constraints can be difficult to solve, an engineering tolerance of $0.2^{\circ} \mathrm{C}$ has been applied to the supply temperature and $7.5 \times 10^{-4} \mathrm{~kg}_{\text {vapor }} / \mathrm{kg}_{\text {dry_air }}$ to the humidity ratio (which is approximately equivalent to $5 \%$ relative humidity at $20^{\circ} \mathrm{C}$ and $50 \%$ relative humidity). Another constraint that impacts the optimization results is that in order to maintain the indoor air quality, the minimum specified quantity of outdoor air entering each zone must be maintained, regardless of the current airflow regime throughout the system. In total, the optimization problem is subject to 11 equality constraints and 127 inequality constraints (Wright et al. 2008). Finally, the behavior of a GA is subject to the value of certain control parameters; the experiments performed in this research are for a single set of algorithm control parameter values, the choice of which is described by Wright et al. (2008).

Example Building Loads. The example building is notionally located in Oklahoma City, Oklahoma, USA, a location that has a continental climate and a large annual range of ambient conditions. The building is orientated so that one mid-level zone faces east and the other west. Nine load conditions have been used in this study, the conditions approximating early morning, midday, and afternoon operation, in each of three different seasons, winter, spring/autumn, and summer. The weight of each load condition has been chosen arbitrarily, with all loads having equal weight except that the spring/autumn loads having a slightly higher weight to reflect that they represent two seasons of operation (spring and autumn). The load conditions have been selected to ensure that a range of operating conditions exist, including conflicting modes of operation; for example, one zone requires heating while the other requires cooling. Conflicting operating conditions have been included to examine the potential for synthesizing truly multizone systems (since a system serving zones that have similar loads is in effect a single-zone system).

Table 2 shows the ambient conditions and the weight applied to the system capacities in calculating the objective function value. Tables 3 and 4 provide the corresponding zone design conditions and loads for the east and west zones. In order to simplify the analysis, the zone latent loads have been fixed across all load conditions. However, the sensible loads vary significantly between load conditions and are driven primarily by the fabric heat transfer and, in particular, the solar gain. Since for some load conditions the temperature and humidity ratios differ between zones, it is evident that the system capacity could be reduced through interzonal airflow (Zhang et al. 2006; Wright and Zhang n.d.).

Minimum System Capacity. Table 5 provides the minimum system capacity at each load condition for the example building (with the minimum fan capacity being taken as zero). The capacities indicate that under optimum operation both zones require full mechanical air conditioning, although some load conditions can be met through free-cooling (indicated by an outside airflow rate higher than the minimum of $0.096 \mathrm{~kg} / \mathrm{s}$ for the east zone and $0.032 \mathrm{~kg} / \mathrm{s}$ for the west zone). Seven different modes of system operation (Table 6) can also be deduced from Table 5. Table 5 also indicates that to achieve the minimum system capacity, the air from the east zone must be exhausted through the west zone during winter operation (Figure 4c) and that this flow configuration is reversed during summer operation (Figure 4b). During spring/autumn operation, the airflow should be exhausted directly from each zone (Figure 4a). 
Table 2. Ambient Design Conditions

\begin{tabular}{cccccc}
\hline Season & Time of Day & Weight & $\begin{array}{c}\text { Temperature, } \\
{ }^{\circ} \mathbf{C}\end{array}$ & $\begin{array}{c}\text { Relative } \\
\text { Humidity, } \\
\mathbf{\%}\end{array}$ & $\begin{array}{c}\text { Humidity Ratio, } \\
\mathbf{k g}_{\text {vapor }} \mathbf{/ k g} \mathbf{d r y}_{\text {drair }}\end{array}$ \\
\hline \hline \multirow{3}{*}{ Winter } & $08: 00$ & 0.1 & -15.6 & 72.0 & 0.0007 \\
& $14: 00$ & 0.1 & -11.1 & 57.0 & 0.0008 \\
& $17: 00$ & 0.1 & -12.2 & 65.0 & 0.0009 \\
\hline \multirow{3}{*}{ Spring/Autumn } & $08: 00$ & 0.1 & 8.9 & 81.0 & 0.0057 \\
& $14: 00$ & 0.2 & 16.7 & 60.0 & 0.0071 \\
& $17: 00$ & 0.1 & 15.6 & 62.0 & 0.0069 \\
\hline \multirow{3}{*}{ Summer } & $08: 00$ & 0.1 & 29.4 & 57.0 & 0.0147 \\
& $14: 00$ & 0.1 & 38.9 & 36.0 & 0.0157 \\
& $17: 00$ & 0.1 & 37.8 & 37.0 & 0.0154 \\
\hline
\end{tabular}

Table 3. East Zone Design Conditions (Negative Load Values Indicate Heat Loss and Positive Heat Gain)

\begin{tabular}{|c|c|c|c|c|c|c|c|}
\hline Season & $\begin{array}{l}\text { Time } \\
\text { of Day }\end{array}$ & $\begin{array}{c}\text { Temperature, } \\
{ }^{\circ} \mathrm{C}\end{array}$ & $\begin{array}{c}\text { Relative } \\
\text { Humidity, } \\
\%\end{array}$ & $\begin{array}{c}\text { Humidity } \\
\text { Ratio, } \\
\mathrm{kg}_{\text {vapor }} / \mathbf{k g}_{\text {dry_air }}\end{array}$ & $\begin{array}{c}\text { Sensible } \\
\text { Load, } \\
\text { kW }\end{array}$ & $\begin{array}{l}\text { Latent } \\
\text { Load, } \\
\text { kW }\end{array}$ & $\begin{array}{c}\text { Minimum } \\
\text { Outside } \\
\text { Airflow } \\
\text { Rate, } \\
\text { kg/s }\end{array}$ \\
\hline \multirow{3}{*}{ Winter } & 08:00 & 20.0 & 50.0 & 0.0073 & 0.61 & 0.60 & 0.096 \\
\hline & $14: 00$ & 22.0 & 50.0 & 0.0082 & -0.35 & 0.60 & 0.096 \\
\hline & $17: 00$ & 22.0 & 50.0 & 0.0082 & -0.54 & 0.60 & 0.096 \\
\hline \multirow{3}{*}{ Spring/Autumn } & 08:00 & 22.0 & 50.0 & 0.0082 & 0.95 & 0.60 & 0.096 \\
\hline & $14: 00$ & 22.0 & 50.0 & 0.0082 & 2.12 & 0.60 & 0.096 \\
\hline & $17: 00$ & 22.0 & 50.0 & 0.0082 & 1.07 & 0.60 & 0.096 \\
\hline \multirow{3}{*}{ Summer } & 08:00 & 20.0 & 50.0 & 0.0073 & 4.39 & 0.60 & 0.096 \\
\hline & $14: 00$ & 24.0 & 50.0 & 0.0093 & 2.17 & 0.60 & 0.096 \\
\hline & $17: 00$ & 22.0 & 50.0 & 0.0082 & 1.92 & 0.60 & 0.096 \\
\hline
\end{tabular}

\section{EXPERIMENTAL RESULTS}

The performance of the optimization has been examined using 41 runs of the optimization algorithm. The trials were performed in two sets, the difference in the two being the number of iterations of the algorithm before termination of the search. An iteration of a GA is known as a generation; in the first set of experiments, the search was run for 20,000 generations. This was reduced to 10,000 generations in the second set of experiments as it was evident that this was sufficient for convergence of the search. The experimental results are examined here in terms of the consistency of the solutions obtained from the algorithm as well as the optimality of the solutions (particularly the best solution found in all trial optimizations).

\section{Algorithm Robustness}

Of the 41 trial optimizations, 14 failed to find a feasible design solution. In all cases, the infeasibility was due to the constraints on the supply air temperature and humidity not being 
Table 4. West Zone Design Conditions

(Negative Load Values Indicate Heat Loss and Positive Heat Gain)

\begin{tabular}{|c|c|c|c|c|c|c|c|}
\hline Season & $\begin{array}{l}\text { Time } \\
\text { of Day }\end{array}$ & $\begin{array}{c}\text { Temperature, } \\
{ }^{\circ} \mathrm{C}\end{array}$ & $\begin{array}{c}\text { Relative } \\
\text { Humidity, } \\
\%\end{array}$ & $\begin{array}{c}\text { Humidity } \\
\text { Ratio, } \\
\mathrm{kg}_{\text {vapor }} / \mathbf{k g}_{d r y \_a i r}\end{array}$ & $\begin{array}{c}\text { Sensible } \\
\text { Load, } \\
\text { kW }\end{array}$ & $\begin{array}{c}\text { Latent } \\
\text { Load, } \\
\text { kW }\end{array}$ & $\begin{array}{c}\text { Minimum } \\
\text { Outside } \\
\text { Airflow } \\
\text { Rate, } \\
\text { kg/s }\end{array}$ \\
\hline \multirow{3}{*}{ Winter } & 08:00 & 18.0 & 50.0 & 0.0064 & -2.02 & 0.20 & 0.032 \\
\hline & $14: 00$ & 20.0 & 50.0 & 0.0073 & 2.60 & 0.20 & 0.032 \\
\hline & $17: 00$ & 20.0 & 50.0 & 0.0073 & 0.64 & 0.20 & 0.032 \\
\hline \multirow{3}{*}{ Spring/Autumn } & 08:00 & 22.0 & 50.0 & 0.0082 & 1.33 & 0.20 & 0.032 \\
\hline & 14:00 & 22.0 & 50.0 & 0.0082 & 2.56 & 0.20 & 0.032 \\
\hline & $17: 00$ & 22.0 & 50.0 & 0.0082 & 1.49 & 0.20 & 0.032 \\
\hline \multirow{3}{*}{ Summer } & 08:00 & 22.0 & 50.0 & 0.0082 & 2.18 & 0.20 & 0.032 \\
\hline & $14: 00$ & 20.0 & 50.0 & 0.0073 & 5.07 & 0.20 & 0.032 \\
\hline & $17: 00$ & 20.0 & 50.0 & 0.0073 & 5.55 & 0.20 & 0.032 \\
\hline
\end{tabular}

Table 5. Minimum Air-Conditioning Process Capacity (Negative Capacity Values Indicate Cooling/Dehumidification and Positive Heating/Humidification)

\begin{tabular}{|c|c|c|c|c|c|c|c|c|c|}
\hline \multirow[b]{2}{*}{ Season } & \multirow[b]{2}{*}{$\begin{array}{c}\text { Time } \\
\text { of } \\
\text { Day }\end{array}$} & \multicolumn{3}{|c|}{ East Zone } & \multicolumn{3}{|c|}{ West Zone } & \multirow[b]{2}{*}{$\begin{array}{c}\text { Min. } \\
\text { Total } \\
\text { Capacity, } \\
\text { kW }\end{array}$} & \multirow[b]{2}{*}{$\begin{array}{c}\text { Airflow } \\
\text { Exhaust } \\
\text { Zone(s) }\end{array}$} \\
\hline & & $\begin{array}{c}\text { Min. } \\
\text { Sensible } \\
\text { Capacity, } \\
\text { kW }\end{array}$ & $\begin{array}{c}\text { Min. } \\
\text { Latent } \\
\text { Capacity, } \\
\text { kW }\end{array}$ & $\begin{array}{c}\text { Outside } \\
\text { Airflow } \\
\text { Rate, } \\
\text { kg/s }\end{array}$ & $\begin{array}{c}\text { Min. } \\
\text { Sensible } \\
\text { Capacity, } \\
\text { kW }\end{array}$ & $\begin{array}{c}\text { Min. } \\
\text { Latent } \\
\text { Capacity, } \\
\text { kW }\end{array}$ & $\begin{array}{c}\text { Outside } \\
\text { Airflow } \\
\text { Rate, } \\
\text { kg/s }\end{array}$ & & \\
\hline \multirow{3}{*}{ Winter } & 08:00 & 2.82 & 0.95 & 0.096 & 2.91 & 0.05 & 0.032 & 6.72 & West \\
\hline & 14:00 & 3.54 & 1.13 & 0.096 & 0.00 & 0.99 & 0.089 & 5.66 & West \\
\hline & $17: 00$ & 3.84 & 1.13 & 0.096 & 0.20 & 0.07 & 0.032 & 5.24 & West \\
\hline \multirow{3}{*}{$\begin{array}{c}\text { Spring/ } \\
\text { Autumn }\end{array}$} & 08:00 & 0.31 & 0.00 & 0.096 & 0.00 & 0.43 & 0.101 & 0.74 & East/West \\
\hline & 14:00 & 0.00 & 0.53 & 0.399 & 0.00 & 1.16 & 0.480 & 1.69 & East/West \\
\hline & 17:00 & 0.00 & -0.03 & 0.167 & 0.00 & 0.59 & 0.233 & 0.63 & East/West \\
\hline \multirow{3}{*}{ Summer } & 08:00 & -5.30 & -2.35 & 0.096 & -2.23 & -0.48 & 0.032 & 10.36 & West \\
\hline & 14:00 & -3.48 & -1.92 & 0.096 & -5.67 & -0.85 & 0.032 & 11.93 & East \\
\hline & 17:00 & -3.37 & -2.17 & 0.096 & -6.12 & -0.82 & 0.032 & 12.49 & East \\
\hline \multicolumn{8}{|c|}{ Weighted Sum } & 5.72 & \\
\hline
\end{tabular}

met. Further inspection of the results indicated that the system operation had been optimized and, therefore, that the infeasibility was due to the search having converged on a system topology that was inherently unable to meet the zone loads.

The 27 feasible solutions are provided in Table 7, which also indicates the performance of the benchmark systems. Table 7 indicates that the majority of the feasible systems have a weighted capacity that lies between those of the single-duct and dual-duct systems. This supports the notion that the standard deviation of the optimized system capacities is low and, therefore, 
Table 6. System Operating Modes, High-Load Building

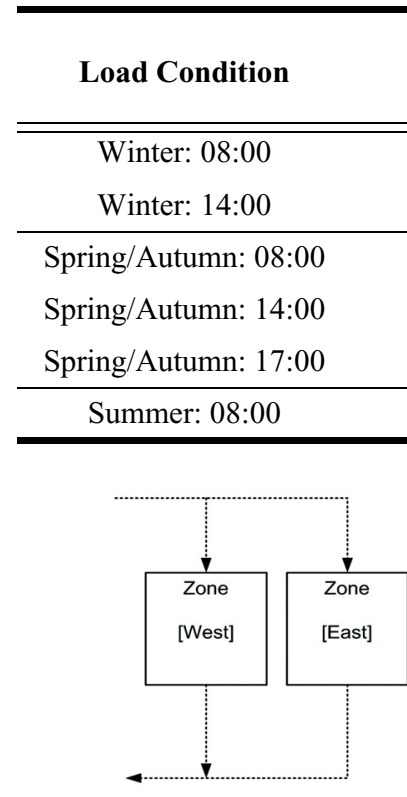

(a)

East Zone

Sensible

East Zone

West Zone

\begin{tabular}{cccl} 
Heat & Humidify & Heat & Humidify \\
Heat & Humidify & Free-cool & $\begin{array}{l}\text { Humidify } \\
\text { Heat }\end{array}$ \\
Zero Capacity & Free-cool & Humidify \\
Free-cool & Humidify & Free-cool & Humidify \\
\hline
\end{tabular}

\begin{tabular}{llll} 
Cool & Dehumidify & Cool & Dehumidify \\
\hline
\end{tabular}

Figure 4. Extract and exhaust airflow configurations.

notwithstanding the fact that algorithm can fail to find a feasible solution, it can be considered to be "robust." Table 7 also indicates that solutions from both experimental sets are evenly distributed throughout the range of feasible solutions, although the best solutions arise from the first experimental set in which the algorithm was run for 20,000 generations (rather than 10,000 generations in the second set).

The algorithm's performance is further analyzed in Table 8, which gives four categories of solutions: infeasible solutions, solutions having a poorer performance than the conventional single-duct and dual-duct systems, solutions having a performance comparable to conventional systems, and systems having a better performance than conventional systems. Table 8 indicates that although there is approximately a one-in-three chance of the search converging onto an infeasible solution, there is a greater chance (one in two) of finding a feasible system that has a performance comparable to the single-duct and dual-duct systems; that is, when the algorithm is run twice there is a high probability that the best of the synthesized systems will have a performance comparable to conventional systems. Further, although it would be necessary to run the optimization on the order of eight times to find a solution having better performance than the conventional systems, the likelihood of finding a feasible solution having a worse performance than the conventional systems is only 1 in 14 .

\section{Optimality of the Synthesized System}

Rather than assess the optimality of all the synthesized systems, the optimality of only the best solution obtained from all 41 trial optimizations is evaluated here. Figure 5 illustrates the best of the synthesized systems. The system has several features that act to minimize the required system capacity. First, the air-conditioning components are evenly distributed between the two zones, there being no centrally located components. This means that the load in each 
Table 7. Feasible Solutions

(All Capacity Values are for the Weighted Sum of the Capacities at Each Load Condition and Include Fan Capacity)

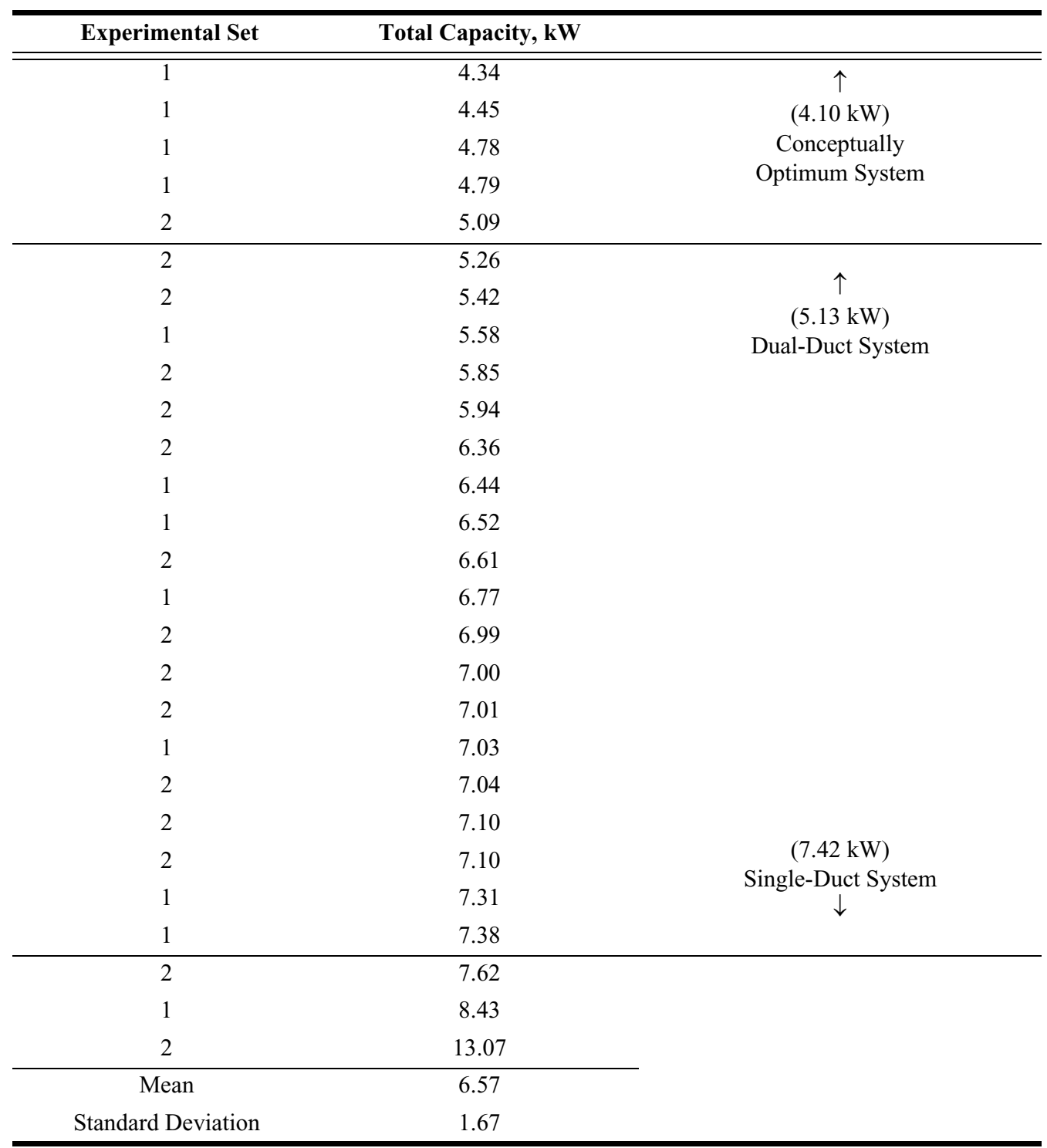

Table 8. Summary of Algorithm Performance

\begin{tabular}{cccc}
\hline System Performance & Number of Solutions, & \multicolumn{2}{c}{ Probability } \\
& - & $\mathbf{\%}$ & $\sim$ ratio \\
\hline \hline Better than conventional systems & 5 & 12.2 & $1: 8$ \\
Equal to conventional systems & 19 & 46.3 & $1: 2$ \\
Worse than conventional systems & 3 & 7.3 & $1: 14$ \\
Infeasible system & 14 & 34.2 & $1: 3$ \\
\hline
\end{tabular}




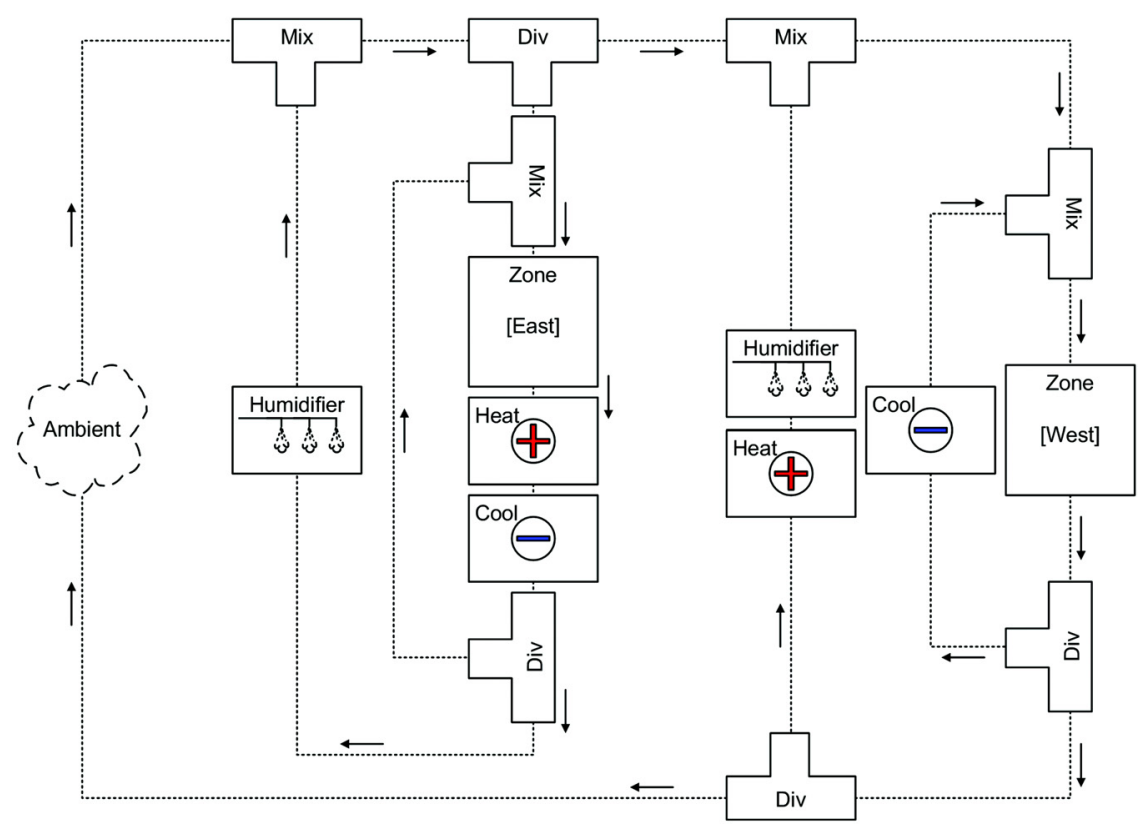

Figure 5. Best of the synthesized systems.

zone can be met by dedicated air-conditioning components and that the high-capacity operation associated with centralized cooling and zonal re-heat will not occur. Second, since the extract air from the east zone is exhausted through the west zone, the system has the potential to transfer energy between the east and west zones and therefore reduce the west zone's loads. Further, the system has independent recirculation paths, which means that the system is always able to operate with the minimum outdoor airflow rate to each zone when required. Finally, note that for the west zone, the air-conditioning components are located in the recirculation legs of the duct system. Since the airflow rate is lower in the recirculation legs than in the supply leg, locating the components in the recirculation leg reduces the pressure loss across the components and therefore the fan capacity; this is most effective during free-cooling operation when the recirculation flow rate is zero.

Table 7 indicates that the general performance of the synthesized systems is comparable to, and in some cases exceeds, the performance of the contemporary systems. However, the optimality of the solutions can only be confirmed by comparing the system capacity to the minimum possible capacity at each load condition (the minimum capacities having been corrected for the tolerance on the supply air conditions; see Appendix).

Since the minimum possible fan capacity has been taken to be zero, the fan capacities are considered separately from the capacities associated with the air-conditioning processes (the minimum possible air-conditioning process capacity being greater than zero for most load conditions). The fan capacities of each of the systems are of similar magnitude, with the single-duct and conceptually optimum system configurations having the lowest fan capacities; the fan capacities are also small compared to the capacities associated with the air-conditioning processes (Wright et al. 2004).

The extent to which the system performs with the minimum possible air-conditioning process capacity is conveniently represented by the system effectiveness. (Equations 1-2 and Appendix). 
Table 9 provides the effectiveness of the best of the synthesized and benchmark systems. During winter operation, the effectiveness of both the single-duct and dual-duct systems is less than 1.0, as both systems are unable to offset the zone loads through the use of interzonal airflow, which, in particular, resulted in the need to humidify the east zone supply air. Conversely, both the conceptually optimum system (Figure 3 ) and the best of the synthesized systems (Figure 5) are able to circulate air between zones and therefore offset the zone loads such that no humidification is necessary (since the humidification load falls within the tolerance on the supply air conditions). Finally, inspection of the system operation indicated that the effectiveness of less than 1.0 for the synthesized system was due to premature convergence of the system operation optimization rather than an inherent flaw in the system configuration.

As might be expected, all systems are $100 \%$ effective during spring/autumn operation, as these seasons are dominated by free-cooling (although there is a small heating load during the early morning). The effectiveness of less than 1.0 for the early morning operation of the synthesized system is due to a slightly higher than necessary heating capacity and therefore what appears to be premature convergence of the system operation optimization.

The poorest performance of the single-duct and dual-duct systems is most evident during summer operation. The single-duct system suffers from the use of the centrally located cooling coil, which is used for both sensible cooling and dehumidification. The centrally cooled and dehumidified air is then reheated before being supplied to the zones. The poor performance is exacerbated by an outdoor airflow rate that is higher than the specified minimum, this being necessary to maintain the indoor air quality (Wright et al. 2004). The performance of the single-duct system is also degraded since it can not promote load reduction by interzonal airflow. For the two-zone system considered here, the dual-duct system is able to operate without the need for zonal re-heat and therefore has a higher effectiveness than the single-duct system. The dual-duct system does, however, suffer from not being able to reduce the system capacity through interzonal airflow; the system also operates with an outdoor airflow rate higher than the specified minimum (Wright et al, 2004). Conversely, the conceptually optimum system is able to operate with maximum effectiveness; the effectiveness values greater than 1.0 for afternoon operation are due to the tolerance on the supply air conditions (see Appendix), whereas the effectiveness of less than 1.0 during early morning operation appears to be due to the premature convergence of the system operation optimization. Similarly, the best of the synthesized systems is also able to avoid the use of simultaneous cooling and heating and is able to operate with the minimum outdoor airflow rate. However, the system effectiveness is less than 1.0 during afternoon operation, as the system is only able to transfer air from the east zone to the west zone, whereas the minimum capacity calculation suggests that the opposite is required to minimize the system capacity (Table 5).

\section{DISCUSSION AND CONCLUSIONS}

The aim of this research was to investigate the synthesis of novel HVAC system configurations using model-based optimization methods. This paper describes the experimental results (the optimization procedure is described by Wright et al. 2008). The experimental approach described herein is focused on evaluating the repeatability of the optimization process and the optimality of the solutions, optimality being judged by comparing the system performance to three benchmark systems and the minimum possible capacity at a given load condition.

The results indicate that multiple runs of the optimization algorithm are required to find a feasible design solution but that approximately two runs of the algorithm is sufficient to find a system design having a performance that is comparable to existing system configurations. Further, eight alternative runs of the algorithm is likely to result in a system that operates with a lower capacity than contemporary systems. Although this indicates a degree of robustness of the algorithm, one in 
Table 9. System Effectiveness

\begin{tabular}{cc|cccc}
\hline Season & Time of Day & $\begin{array}{c}\text { Single-Duct } \\
\text { System }\end{array}$ & $\begin{array}{c}\text { Dual-Duct } \\
\text { System }\end{array}$ & $\begin{array}{c}\text { Conceptually } \\
\text { Optimum } \\
\text { System }\end{array}$ & $\begin{array}{c}\text { Best } \\
\text { Synthesized } \\
\text { System }\end{array}$ \\
\hline \hline \multirow{3}{*}{ Winter } & $08: 00$ & 0.97 & 0.96 & 1.00 & 1.00 \\
& $14: 00$ & 0.86 & 0.85 & 1.00 & 0.90 \\
\hline \multirow{3}{*}{ Spring/Autumn } & $17: 00$ & 0.95 & 0.94 & 1.00 & 0.96 \\
& $08: 00$ & 1.00 & 1.00 & 1.00 & 0.87 \\
& $14: 00$ & 1.00 & 1.00 & 1.00 & 1.00 \\
& $17: 00$ & 1.00 & 1.00 & 1.00 & 1.00 \\
\hline \multirow{3}{*}{ Summer } & $08: 00$ & 0.91 & 0.91 & 0.97 & 1.00 \\
& $14: 00$ & 0.36 & 0.88 & 1.07 & 0.94 \\
& $17: 00$ & 0.56 & 0.85 & 1.09 & 0.97 \\
\hline
\end{tabular}

three runs of the algorithm are likely to result in an infeasible solution. The infeasibility is typically due to the search having converged on a system configuration that is inherently unable to provide the required supply air conditions. This characteristic of the search is partly a function of the constraints imposed on the supply air conditions. An approach to eliminating these constraints has been proposed by Sowell (2002) (this is a possible subject for future research).

Although multiple runs of the algorithm are required to find near-optimum system designs, it should be emphasized that the algorithm operates without any embedded or a priori design knowledge, the only information used by the search to judge the suitability of a design solution being the capacity and feasibility of the system (Wright et al. 2004; Wright et al. 2008). The fact that existing system designs are a result of over a century of human research and development indicates the significance of the design task and the success of the algorithm in synthesizing systems that have equal or better performance than the existing systems.

The optimality of the best of the synthesized systems was examined in comparison to the minimum possible capacity for the system. The system operated with near-optimal performance that was significantly better than the example single-duct and dual-duct benchmark systems. The best of the synthesized systems had several novel features that contributed to its performance (and that match those of a conceptually optimum system).

It can be concluded that the optimization approach is able to synthesize near-optimum system configurations that are likely to have performance equal to or better than existing system configurations. The algorithm, however, requires multiple runs in order to find reliable solutions, a fact that should be addressed in future research. The current algorithm represents a significant step toward the design of software systems that are able to synthesize new and optimum HVAC system configurations.

\section{REFERENCES}

Caldas, L.G., and L.K. Norford. 2002. A design tool based on a Genetic Algorithm. Automation in Construction 11:173-84.

Nassif, N., S. Kajl, and R. Sabourin. 2005. Optimization of HVAC control system strategy using two-objective Genetic Algorithm. HVAC\&R Research 11(3):459-86. 
Sowell, E. 2002. Oral Communication. Summarized in Wright et al. 2004, Appendix F.

Wang, W., R. Zmeireanu, and H. Rivard. 2005. Applying multi-objective Genetic Algorithms in green building design optimization. Building and Environment 40(11):1512-25.

Wright, J.A. 1996. HVAC optimisation studies: Sizing by Genetic Algorithm. Building Services Engineering Research and Technology 17(1):7-14.

Wright, J.A., H.A. Loosemore, and R. Farmani. 2002. Optimization of building thermal design and control by multi-criterion Genetic Algorithm. Energy and Buildings 34(9):959-72.

Wright, J.A., Y. Zhang, P.P. Angelov, R. Buswell, and V.I. Hanby. 2004. Building system design synthesis and optimization. Final Report on Research Project RP-1049. Atlanta: American Society of Heating, Refrigerating and Air-Conditioning Engineers, Inc.

Wright, J.A., Y. Zhang, P.P. Angelov, R.A. Buswell, and V.I. Hanby. 2008. Evolutionary synthesis of HVAC system configurations: Algorithm development. HVAC\&R Research 14(1).

Wright, J.A., and Y. Zhang. n.d. The minimum capacity of an HVAC secondary system (with capacity reduction by interzonal airflow). Submitted for publication to $H V A C \& R$ Research.

Zhang, Y., J.A. Wright, and V.I. Hanby. 2006. Energy aspects of HVAC system configurations: Problem definition and test cases. $H V A C \& R$ Research 12(3c):871-88.

\section{APPENDIX}

\section{Minimum Capacity Correction}

The thermodynamic minimum capacity of a multizone HVAC system is equivalent to the sum of the zone and outside air loads on each zone after the zone loads have been minimized through the circulation of air between zones (Wright and Zhang n.d.). For the two-zone optimization problem considered herein, the extent to which air should be circulated between zones, together with the outdoor airflow rate to each zone, has been determined through a sequential logic-based calculation (Wright et al. 2004). The logic-based calculation assumes that the supply air temperature and humidity ratio are maintained to meet the zone loads exactly. However, although constrained, the supply air conditions in the optimization are subject to a tolerance. Therefore, in the analysis presented here, the calculated minimum capacity is corrected for each set of the optimization results using the optimized supply air mass flow rate and degree of tolerance utilized by a solution:

$$
\dot{Q}_{i}^{\text {min }} \Rightarrow \sum_{z=1}^{n z}\left(\left(\dot{Q}_{i, z}^{\text {min, sensible }}-\dot{m}_{i, z} C_{p} \Delta T_{i, z}\right)+\left(\dot{Q}_{i, z}^{\text {min, latent }}-\dot{m}_{i, z} L \Delta w_{i, z}\right)\right)
$$

where

$\dot{Q}_{i, z}^{\text {min, sensible }} \quad=\quad$ calculated minimum sensible capacity for load condition $i$ and zone $z$

$\dot{Q}_{i, z}^{\text {min, latent }} \quad=\quad$ calculated minimum latent capacity for load condition $i$ and zone $z$

$\dot{m}_{i, z} \quad=$ optimized supply air mass flow rate

$\Delta T_{i, z}$ and $\Delta w_{i, z}=$ differences in the supply air temperature and humidity ratio from that determined for a zero tolerance (note that $\Delta T_{i, z}$ and $\Delta w_{i, z}$ will both be less than or equal to the value of the tolerance provided that the optimized solutions satisfy the constraint on the zone supply air condition)

$C_{p}$ and $L=$ sensible and latent heat capacities of air at the supply air temperature

Note that Equation A1 is formulated1 with the convention that all capacities have a positive value. 
Although this procedure corrects the minimum capacity for the energy associated with the tolerance on the supply air conditions, it does not account for the fact that the tolerance can result in a different control priority from that determined by the logic-based minimum capacity calculation, the control mode being determined to ensure that both the zone sensible and latent loads are met with the minimum capacity. Under some conditions, either the sensible or the latent load will dominate the control strategy and, in particular, the use of the outdoor air in free-cooling or the load reduction by interzonal airflow. For example, although the outdoor air may be used in free-cooling to reduce the sensible load, the ambient conditions may be such that the latent load is increased by the outdoor airflow. Under these conditions, the outdoor airflow rate will be dictated by the trade-off between the reduction in sensible load and the increase in latent load. The trade-off for the optimization result can be different from that for the zero-tolerance logic-based minimum capacity calculation. For example, the latent load may fall within the tolerance on the supply air conditions in the optimization, which would then give complete priority to the sensible load and perhaps allow an increase in the use of free-cooling and, therefore, a lower capacity than predicted using the zero-tolerance logic-based capacity calculation; this in turn could result in a system effectiveness of greater than 1.0. Note that the supply air condition tolerance also impacts the use of interzonal airflow, the choice of interzonal airflow rates also being a function of the trade-off between the sensible and latent loads and, therefore, the tolerance on the supply air conditions. 